総説

\title{
Bi 系高温超伝導体に対する添加効果
}

高田潤

岡山大学工学部精密応用化学科, テ700 岡山市津島中3-1-1.

\section{Addition of Some Elements to High-Tc Bi-Sr-Ca-Cu-O Superconductor}

Jun Takada

Department of Applied Chemistry, Okayama University, Tsushima-naka, Okayama 700.

Received January 27, 1992

The addition effects of $\mathrm{Pb}, \mathrm{Ba}$ and $\mathrm{Li}$ to the 2223 phase in the $\mathrm{Bi}-\mathrm{Sr}-\mathrm{Ca}-\mathrm{Cu}-\mathrm{O}$ system on the properties and the formation process have been reviewed.The incorporation of $\mathrm{Pb}$ and $\mathrm{Ba}$ into the 2223 phase and the increase in Tc has been experimentally discussed.The substitution sites of the elements have been interpreted on the basis of the results of the equilibrium phase diagrams for the 2201 phase reported so far.The formation process of the $\mathrm{Pb}$ and $\mathrm{Pb}+\mathrm{Ba}$ doped 2223 phase has also been discussed with particular attention to liquid formation and wettability.

\section{I 、はじめに}

Bi-Sr-Ca-Cu-O系超伝導体の発見)以来現在に至る まで、この系ではTc 107Kの2223相の単相試料は得 られていない。しかし、筆者らは、この系に $\mathrm{Pb} を$ 加することによって2223相の生成が促進されること を見い出し2、更に単相試料の合成も可能であるこ とを報告した ${ }^{344}$ 。また高 $\mathrm{Pb}$ 組成で $\mathrm{Tc} の$ 上昇を見い出 した5)。このようにBi系2223相では元素添加によっ て顕著な効果を示す。他方2201相、2212相について は単相組成域が明らかにされておりのク、それぞれの 添加効果は詳細に研究されている8-12)。このような 元素添加効果は、以下に示寸二種類の効果に大別さ れる。第一の効果は、添加元素が超伝導体に固溶置 換することによって、超伝導体の結晶の棈造や超伝
導特性に影響を及はす直換効果である。第二の効果 は、超伝導相の生成機構に影響を及はす効果であ る。本稿では、Bi系超伝導体への元素源加を、主と して筆者らの共同研究グループでこれまで取り扱っ てきたPb、BaおよびLiの2223相への添加に関する実 験結果に基づいて、上記の二つの観点から概説す る。

\section{II. 罡换奻果}

ここでは、2223相への添加元索の固溶を確認し た実験結果を示した後、固溶にともなう超伝導特性 の変化を紹介する。さらに2201相に関する状態图的 䂰究結果に基づいて2223相での元素の置換位置を検 討する。 


\section{1 固潧の実険的確现}

添加元素の固溶を実験的に確認する方法には 種々の方法がある。筆者らは、2223相結晶中のPb扔 よびBaの固溶について、X線波長分散(WDX)分析法 によるこれらの元素の特性X 線を検出する直接的な 確認方法と粉末X 線回折法による格子定数の変化を 検討する間接的な確認方法を用いだ.12)。

Fig.1に、異なる $\mathrm{Pb}$ 量 $(\mathrm{Bi}: \mathrm{Pb}: \mathrm{Sr}: \mathrm{Ca}: \mathrm{Cu}=(\mathrm{a}) 0.726:$ 0.374:1:1:1.65, (b)0.90:0.20:1:1:1.6)の䂝料 $850^{\circ} \mathrm{C}-192 \mathrm{~h}$ 焼成)における2223相中のBi とPbのWDX(L $\alpha)$ の結果5) を示す。両者とも $\mathrm{Pb}$ 特性X線が検出されると共 に、低 $\mathrm{Pb}$ 試料(b)よりも高 $\mathrm{Pb}$ 試料(a)の方か $\mathrm{Pb}$ の特性 $\mathrm{X}$ 線強度が高いことから、2223相結晶中にPbが固溶し ていると判断される。Ba添加試料についても同様の 方法で2223相粒子からBa-Laを検出し、Baが2223相 結晶中へ固溶していることを確認した ${ }^{(3)}$ 。

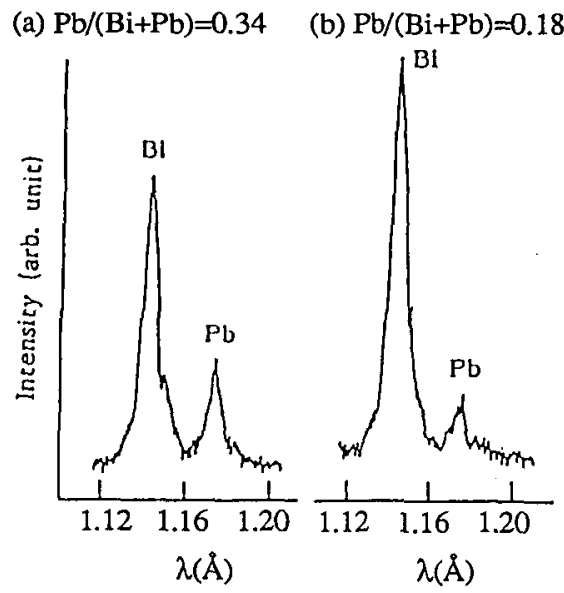

Fig.1 WDX spectra of $\mathrm{Pb}$ and $\mathrm{Bi}$ for the samples with a composition of $\mathrm{Bi}: \mathrm{Pb}: \mathrm{Sr}: \mathrm{Ca}: \mathrm{Cu}=$ (a) 0.726:0.374:1.0:1.0: 1.65 and (b) $0.90: 0.20: 1.0: 1.0: 1.6^{5)}$.

Fig.2に、組成Bi:Pb:Sr:Ca:Cu=0.9:0.2:1:1:1.6の高温 相へBaを添加した場合の格子定数の变化を检討した 結果 ${ }^{13)}$ を示す。Ba添加量 $\mathrm{x}=0$ と0.2の試料 $\left(850^{\circ} \mathrm{C}-78 \mathrm{~h}\right.$ 焼 成)の(200)、(0014)回折ピークを検討した。その結

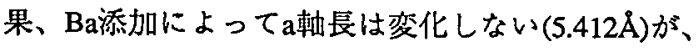
c軸長は $\mathrm{x}=0$ での $37.10 \AA$ から $\mathrm{x}=0.20 て ゙ 37.20 \AA$ まで増加 することが明らかになった。Pb添加試料についても 同样の結果(Fig.1(a)の試料でc軸長のみが $37.20 \AA$ へと 増加）が得られているら。Liについては、格子定数 の変化はないと報告されている(4)。因に、LiはWDX 分析によっては原理的に检出できない。

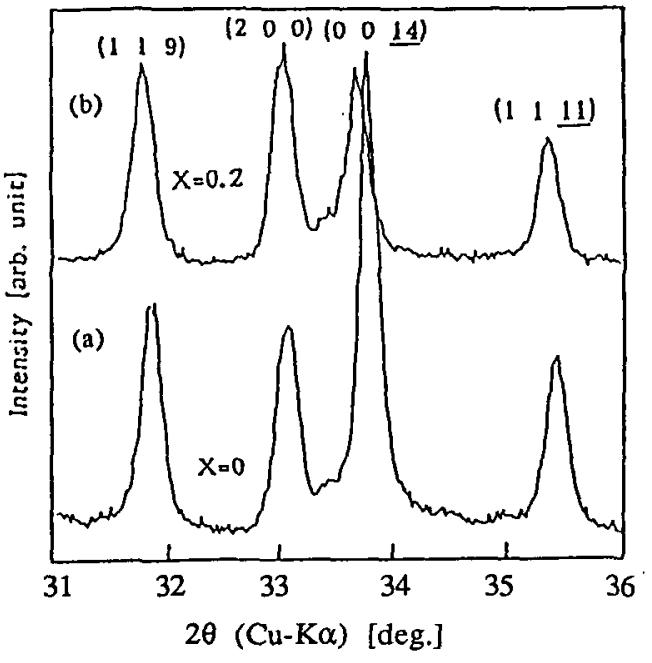

Fig.2 XRD patterns of samples with $\mathrm{x}=$ (a) 0 and (b) 0.2 in $\mathrm{Bi}_{0.9} \mathrm{~Pb}_{0.2} \mathrm{Sr}_{1.0} \mathrm{Ba}_{x} \mathrm{Ca}_{1.0} \mathrm{Cu}_{1.6} \mathrm{O}_{z}^{13}$.

\section{2 趣伝篮特性}

$\mathrm{Pb}$ よび $\mathrm{Pb}+\mathrm{Ba}$ の固溶試料の電気抵抗一温度曲線

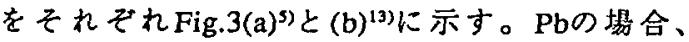
$\mathrm{Tc}(\mathrm{R}=0)$ は低 $\mathrm{Pb}$ 組成で 109Kから高Pb組成で116Kまて
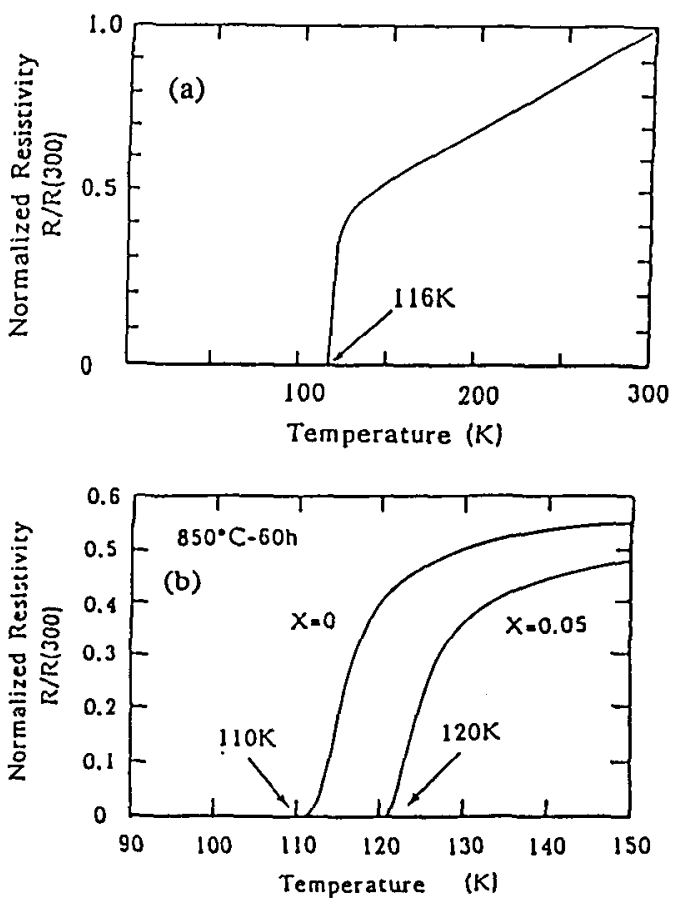

Fig.3 Temperature dependence of electrical resistivity for (a) Pb-rich samples) and (b) Ba-free and Ba-doped samples ${ }^{13)}$. 
上昇する。一方 $\mathrm{Pb}+\mathrm{Ba}$ の場合、 $\mathrm{Ba}$ 算添加 $(\mathrm{x}=0$ :低 $\mathrm{Pb}$ 組 成)で109Kを示すのに対し、Ba固溶 $(x=0.05)$ にっって 120Kまで上昇する。これらのTcは带磁率測定に よっても確認された。

Li添加材(Bi:Pb:Sr:Ca:Cu:Li=0.96:0.24:1:1.1:1.6:x) $)^{14)}$ で は、 $\mathrm{x}=0.05$ で $\mathrm{Tc}(\mathrm{R}=0)=116 \mathrm{~K}$ を示したが、複素帯磁率

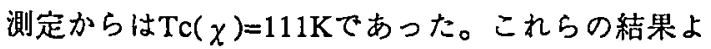
り、 $\mathrm{Tc}=116 \mathrm{~K} の 2223$ 相は $\mathrm{T} c=111 \mathrm{~K} の 2223$ 相の粒子表 面に極薄く生成しているものと推测される。

\section{3 祭換位置}

池田らは、詳細な状態図砳究の結果より2201相

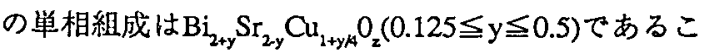
とを明らかにしだ)。更に、この相へのPbとBaの固 溶組成域抢よび置換位置を明らかにした89\%。Fig.4に $\mathrm{Pb}$ 固溶による単相組成域 $\mathrm{Bi}_{2+y-\mathrm{x}} \mathrm{Pb}_{\mathrm{x}+\mathrm{z}} \mathrm{Sr}_{2 \mathrm{y}-\mathrm{z}} \mathrm{Cu}_{1+y / 4} \mathrm{O}_{8}$ を示 す。PbはBiとSrの二つの位置に置換可能 $(x \leqq 0.4 、 z$ ミ0.4)である。Bi位置に置換した場合は結晶は斜方 晶に歪み、またx 0.4で变調檴造の無い超伝導相が

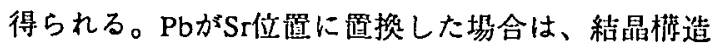
は正方晶を保つ。また、Bi位圆に圆換したPbは不安 定で、低温 $\left(700^{\circ} \mathrm{C}\right)$ での炾成で容易に結晶から放り出 される特徽がある。2201相へのBa置掺は、Sr位置の みであることも最近明らかとなったり。

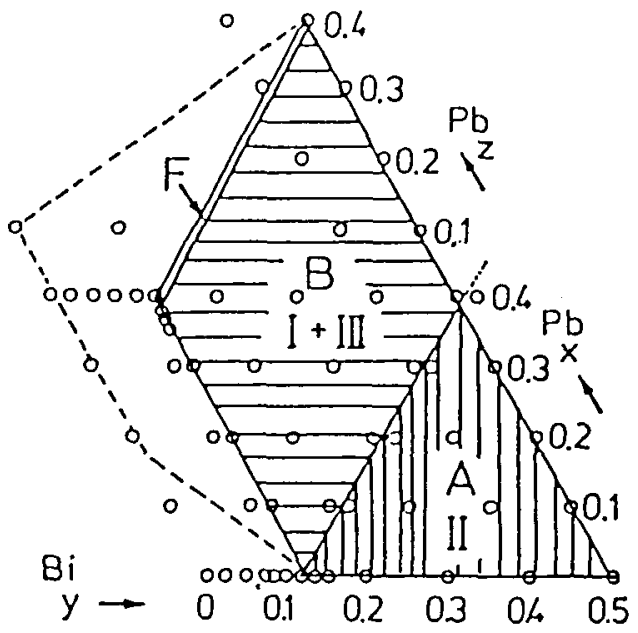

Fig.4 Monophasic composition range in the Pb-substituted 2201 phase $^{8}$.

以上の2201相の結果から、2223相中のPbも Bi位置の みならずSr位置へも直換し、またBaはSr位置にのみ 直換していると類推される。特に $\mathrm{Tc}=117 \mathrm{~K}$ 示す高
$\mathrm{Pb}$ 組成の2223相のではSr位置に置換した $\mathrm{Pb} ゙$ Tcの上 昇と関連していることも考六られる。

Liについては、川合らが2212相に関して䂙究を行 い、Cu位置に置換すると提案している12)が、状熊図 的な研究など今後詳細な㭘討を行う必要がある。

\section{III. 生成控样}

現在のところ、2223相は2212相と同様包晶反忍 で生成すると考えられる。この場合液相が重要な役 割を果たす。従って、2223相の生成を検討するため には、(1)液相の生成する温度 $\left(\mathrm{T}_{\mathrm{L}}\right)$ と液相組成、(2) $\mathrm{T}_{\mathrm{L}}$ 以下の温度での平衡北存相、(3)2223相の生成の初期 過程、(4)液相との始れ性を明らかにする必要があ る。はしめに、 $\mathrm{Pb}$ 添加の場合について論ずる15)。ま

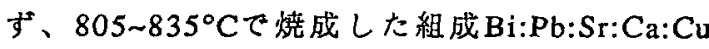
$=0.9: 0.2: 1: 1: 1.6$ 試料のXRDバターンを詳細に検討 し、以下の結果を得た。 $825^{\circ} \mathrm{C} て ゙ 2223$ 相の生成が認 められる。同時にこの温度で液相が生成する $\left(\mathrm{T}_{\mathrm{L}}=825^{\circ} \mathrm{C}\right)$ 。また $\mathrm{T}_{\mathrm{L}}$ 以下での平衡共存相は 2212 相、 $\mathrm{Ca}_{2} \mathrm{PbO}_{4} 、 2201$ 相とCuOである。 $825^{\circ} \mathrm{C} て ゙ は 、 815^{\circ} \mathrm{C}$ 以 下では認められた2212相の焉調槽造による回折ビー ク $\left(2 \theta=36.8^{\circ}\right)$ が消失していることから、夜相が生成 すると、速やかに2212相にPbが固溶し、变調權造の 無い2212*相が生成する。次に、 $\mathrm{T}<\mathrm{T}_{\mathrm{L}}$ での共存相の 中で種々の組合せを考えて熱分析を行なった結果、 2201相: $\mathrm{Ca}_{2} \mathrm{PbO}_{4}=7: 3$ (モル比)の組成において $825^{\circ} \mathrm{C} て ゙$ 液相を生成することが判った。更に、この組成の 2201 相と $\mathrm{Ca}_{2} \mathrm{PbO}_{4}$ 混合粉を用いて、2201相、2212相と 2223相と液相の好れ性を検討した。この液相は、 2201相と2212相は好すが、2223相は妨さないこ とが明らかになった。また、X線的に少量の2223相 が生成した場合でも電気抵抗は鋭く減少する。以上 の結果より $\mathrm{Pb}$ 添加の場合の 2223 相の生成過程として

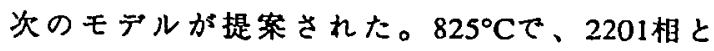
$\mathrm{Ca}_{2} \mathrm{PbO}_{4}$ から生成する液相は2212“相と反応し、2212。 相粒子表面に2223相を生成する。この2223相には液 相はぬれにくいために、包晶反応で更に2223相が生 成するには長時間の熟処理を要すると考えられる。 従って、2223相の単相化には粉碎が効果的である。

$\mathrm{Pb}$ と Baを同時に添加した場合、部分溶融温度は 低下し、2223相の生成が促進させること、粒成長も

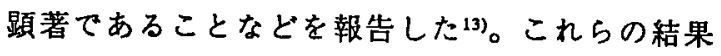
は、 $\mathrm{Ba}+\mathrm{Pb}$ 添加の場合は $\mathrm{Pb}$ 単独添加の場合とは異 なった生成過程により2223相が生成することを示唆 
している。特により低温での液相の生成反応とその 液相が2223相をぬらすことが推測される。詳細な生 成機構を明らかにするため現在研究を進めている。

\section{V. おわりに}

以上述べたごとく、現在までに2.223相に対する $\mathrm{Pb} \mathrm{Ba}$ の添加効果についてかなり明らかになってき ているが、2201相や2212相と比僌すると、まだまだ その詳細が解明されたとは言い難い。これは、2223 相の生成に関する複雑さにより再現性が十分でない こと、基礎データを与えるべき $\mathrm{Pb}$ 䈎添加材で単相試 料が得られないこと、さらにはPb添加材での単相組 成域が明らかでないことなどに起因している。従っ て、今後2223相の線材などへの実用化や超伝導機構 の解明を目指すためには、先ずこれらの問題点をよ り明確に把挃し、その上でそれらを明らかにする基 碟的な研究がますます重要である。

\section{文䘞}

(1) H.Maeda, Y.Tanaka, M.Fukutomi and T.Asano: Jpn.J.Appl.Phys., 27(1988), L209.

(2) M.Takano, J.Takada, K.Oda, H.Kitaguchi, Y.Miura, Y.Ikeda,Y.Tomii and H.Mazaki: Jpn.J.Appl.Phys., 27 (1988), L1041.

(3) Y.Ikeda, M.Takano, Z.Hiroi, K.Oda, H.Kitaguchi, J.Takada, Y.Miura, Y.Takeda, O.Yamamoto and H.Mazaki: Jpn.J.Appl.Phys., 27(1988), L2067.

（4）高田, 小田, 江木, 北口, 尾坂, 三活, 池田, 高野,
冨井,岡、山本: 粉体抢よび粉末治金, 36(1989)， 527.

(5) J.Takada, H.Kitaguchi, T.Egi, K.Oda, Y.Miura, H.Mazaki, Y.Ikeda, Z.Hiroi, M.Takano and Y.Tomii: Physica C, 170(1900), 249.

(6) Y.Ikeda, H.Ito, S.Shimomura, Y.Oue, K.Inaba, Z.Hiroi and M.Takano: Physica C, 159(1989), 93.

(7) G.S.Grader, E.M.Gyorgy, P.K.Gallagher, H.M.O'Bryan, D.W.Johnson,Jr., S.Sunshine, S.M.Zahurak, S.Jin and R.C.Sherwood: Phys.Rev., B38(1988), 757.

(8) Y.Ikeda, Z.Hiroi, H.Ito, S.Shimomura, M.Takano and Y.Bando: Physica C, 165(1989), 1889.

（9）池田, Than-Min-Kyaw, 広井, 高野, 坂東: 粉体押 よび粉末治金, 38(1991)，283.

(10) N.Fukushima, H.Niu, S.Nakamura, S.Takano, S.Takagi and S.Kawai:Physica C, 159(1989), 777.

（11）伊藤,池田,広井, 高野, 坂東: 粉体掞よび粉末治 金 38(1991), 279.

(12) T.Kawai, T.Horiuchi, K.Mitsui, K.Ogura, S.Takagi and S.Kawai: Physica C, 161(1989), 561.

（13）藤原, 難波, 高田, 広井, 池田, 高野: 粉体扔よび 粉末冶金, 38(1991), 1039.

（14）大原，遠藤，江木，難波，高田，池田，高野，坂東， 間崎: 粉体および粉末治金, (印刷中).

(15) Y.Ikeda, H.Ito, S.Shimomura, Z.Hiroi, M.Takano, Y.Bando, J.Takada, K.Oda, H.Kitaguchi, Y.Takeda and T.Takada: Physica C, (inpress). 